\title{
Constipation in Iranian-Islamic Traditional Medicine: The Origin of
}

\section{Diseases}

\author{
Mehrdad Zeinalian, ${ }^{1}$ Mehdi Eshaghi, ${ }^{2}$ Homayoun Naji, ${ }^{3}$ Sayed Mohammad Masoud Marandi, ${ }^{4}$ and \\ Sedigheh Asgary,"
}

\author{
${ }^{1} \mathrm{MD}, \mathrm{MPH}$, PhD of Molecular Medicine, Entekhab Cancer Control Center (Isfahan), ALA Charity Foundation, Isfahan, Iran \\ ${ }^{2}$ MD, Entekhab Cancer Control Center (Isfahan), ALA Charity Foundation, Isfahan, Iran \\ ${ }^{3}$ M.Sc. of Anesthesia, Entekhab Cancer Control Center (Isfahan), ALA Charity Foundation, Isfahan, Iran \\ ${ }^{4} \mathrm{MD}$, Internist, Entekhab Cancer Control Center (Isfahan), ALA Charity Foundation, Isfahan, Iran \\ ${ }^{5}$ Prof, Isfahan Cardiovascular Research Center, Cardiovascular Research Institute, Isfahan University of Medical Sciences, Isfahan, Iran \\ "Corresponding author: Sedigheh Asgary, Prof, Isfahan Cardiovascular Research Center, Cardiovascular Research Institute, Isfahan University of Medical Sciences, Isfahan, Iran. \\ E-mail: sasgary@yahoo.com
}

Received 2016 August 06; Revised 2016 November 05; Accepted 2017 February 23.

\begin{abstract}
Context: Constipation as a common morbidity among people is related to many disorders. Iranian-Islamic traditional medicine (IITM) is an ancient comprehensive medicine school that has a holistic attitude toward human health and disease. Constipation is considered by scholar IITM as the origin of many human disorders. This study aimed to describe viewpoints of IITM scholars toward constipation and its management.

Evidence Acquisition: The main ancient resources in IITM were reviewed and a structural description was created about constipation and its management.

Results: According to IITM, constipation is defined as defecation less than one time daily with firm and dry consistency. It is considered in IITM as a sign of maltempered body that if prolonged, could lead to the accumulation of harmful homors and its associated diseases like cancer. Some general recommendations of IITM help us to prevent and treat constipation; such as chewing food well, avoid of dry cold fiberless diet, regular aerobic exercise, and correction of body temperament. Moreover, diet therapy with high fiber fruits and vegetables, manipulative therapy such as abdominal massage with warm oils, and medication with herbal laxative or purgative drugs are specific therapeutic methods for constipation recommended by IITM scholars.

Conclusions: It seems the holistic attitude of IITM toward constipation and comprehensiveness of its recommendations could be considered in health-related interventions and could ensure community health promotion.
\end{abstract}

Keywords: Constipation, Iranian, Islamic, Traditional Medicine

\section{Context}

Chronic constipation (CC) is a common morbidity that affects $2 \%-27 \%$ of general population in all communities. These variations are due to different definitions and life styles $(1,2)$. Annually, a significant portion of health-related costs is assigned to manage CC and its associated complications (3-5). For example, just in England, a cost of $£ 60$ million is annually allocated to laxatives (6). It is rather mental and physical impairments associated with CC that affect quality of life of people (7). According to some studies, the impact of CC on quality of life is sometimes more severe than the effect of some other chronic disorders like asthma, cardiovascular diseases, and arthritis (8-10). Although in modern current medicine (MCM), CC is considered as a gastrointestinal symptom and morbidity than a risk factor for some other chronic disorders, some studies have presented the significant role of CC in development of some chronic severe diseases like cancer (11-13).

Iranian-Islamic traditional medicine (IITM) is an ancient comprehensive medicine school that has been born of integration of both Iranian traditional medicine, as a several-thousand year school, and Islamic medicine, inspired of Holy Quran and Ahl-ol-Bayt doctrine (14-16).

In contrast to MCM, IITM scholars believe CC is not only a gastrointestinal morbidity, but also a condition leading to many chronic disorders and a sign for maltemperament state of the body. Accordingly, treatment of CC not only is essential for getting rid of its complications but also is the best way to prevent from many maltemperament-related disorders (17). In this paper, we discuss IITM attitude toward constipation and its differences with definitions in MCM. 


\section{Evidence Acquisition}

We reviewed the most important ancient resources of IITM, including Canon of Medicine by Avicenna (980 1037 AD), Zakhire-ye-Kharazmshahi by Jorjani (1042 - 1137 $\mathrm{AD})$, and Gharabadian-e-Kabir and Kholasat-ol-Hekmaa by Aghili-Khorasani (1722 - 1800 AD). These ancient books as well as a few published papers within IITM were investigated to explore a description toward constipation, its classification, and its management, according to IITM scholars.

\section{Results}

\subsection{Definition of Constipation in Modern Current Medicine}

Based on MCM, there are some standard criteria as Rom III in which a combination of criteria including objective (frequency of defecation, need to manipulation for defecation) and subjective (stool color, stool consistency, incomplete evacuation, feeling of bowel obstruction) symptoms are used to define constipation $(1,18)$. According to this definition, stool frequency below 3 times per week is considered as constipation.

\subsection{Definition of Constipation in Iranian-Islamic Traditional Medicine}

Constipation in IITM is defined more stringent than in MCM. At first, we should know the definition of normal defecation in IITM according which its frequency must be 2 - 3 times per day, after eating each main food, with these properties: color is usually light yellow, fecal odor is neither bad smell nor odorless, and fecal consistency is formless not very loose (as consistency of honey). Accordingly, the stool amount in constipation is less than the eaten food, its consistency is firm and dry, and its interval is more than 12 - 24 hours $(16,19,20)$.

\subsection{Interpretation of Constipation in Iranian-Islamic Tradi-} tional Medicine

IITM scholars believe that constipation is a significant sign of mal-temperament, which if prolonged could lead to other chronic disorders. Human fitness, according to IITM, is the result of a balance in four natural body fluids: blood, phlegm, bile, and soda. This balancing is possible via four digestive processes through gastrointestinal tract, liver, blood, and cells, respectively. If each of these processes is disturbed, it will lead to mal-temperament (Soo-emazaj) and pathologic accumulation of the burned black bile in different organs (16-18). The output of the first digestive process is called Boraaz (feces) by IITM scholars. $\mathrm{CC}$ is the result of digestive dysfunction in the first process that could lead to dysfunction of other subsequent digestive processes through liver, blood, and cells. During $\mathrm{CC}$, the normal digestive path of natural humors is obstructed that causes pathological accumulation of burned humors in different organs. In this case, toxins and waste substances are reabsorbed via intestine and their excretion path changes to other systems like skin and respiratory tract: a process that could lead to some pathological defects such as eczema and asthma in these organs (21). This is why CC is considered in IITM as "Omm-ol-Amraz", the origin of diseases. According to cannon in medicine of Avicenna, it could be a main cause for more than seventy disorders (20).

\subsection{The Causes of Constipation}

According to IITM, constipation is due to both extracolonic and intracolonic reasons.

The most important extracolonic reasons include (16, 20, 22-25):

1. Nutritional causes: All dry and cold temper foods and fruits could lead to constipation. Some of the most common of them are corn, rice, dried meat, white flour, walnut, scrambled eggs, yogurt, cheese, most fast foods, sour apple, pomegranate, and banana.

2. Some drugs: for example, diuretics, opiates, and antidepressants.

3. Weakness of disposal force: eating low amount of food or retention of stool for a long time could gradually lead to weakened disposal muscles and constipation.

4. Reduced bile effusion (Ensebab): constipation occurs when bile effusion to intestine reduces to amounts not enough for disposal stimulation.

5. Hot-temperament body or liver: it could lead to loss of gastrointestinal moisture and constipation.

6. Defecation restraint: stress-induced restraint of defecation in some conditions such as traveling could cause constipation.

7. Indulgence in sexual intercourse: it could lead to weakened abdominal muscles as determinant muscles to induce defecation. It would be more efficient to cause constipation if it is usually done with full stomach.

8. Severe cold environment: Body warmth transmits to internal organs in severe cold weather conditions, leading them to dry. Some of the most important intracolonic reasons of constipation according to IITM include $(16,19,20$, 22, 26-28):

9. All obstructive causes of intestine: every inflammation, mass or large polyps, some type of worms, accumulation of very dried stool, herniation and some other anatomical disorders can lead to bowel obstruction and constipation.

10. Intestinal numbness due to severe coldtemperament: It could lead to chronic stool retention 
and moisture reabsorption, an event causing constipation.

11. Compensatory high water reabsorption: chronic constipation is seen in some labors working in very dry and hot workplaces like beside the glass or casting furnaces. Severe exercise in very hot weather can also cause constipation. It is due to compensatory high water reabsorption in intestine leading to dry stool and constipation.

12. Some water consuming parasites: these can lead to dried stool and constipation.

\subsection{Treatment of Constipation}

\subsubsection{Treatment in Modern Current Medicine}

Constipation is treated in MCM by non-medical and medical therapy. At first, non-medical therapy is recommended by life style modification to an active model with consuming high-fiber foods and more liquids. If nonmedical interventions are not efficient, medical therapy is advised using purgative or laxative drugs. When nonmedical and medical methods are not efficient, surgical options would be final therapeutic interventions for severe chronic constipation $(29,30)$.

\subsubsection{Treatment in Iranian-Islamic Traditional Medicine}

Treatment of constipation in IITM, similar to other disorders, is administered according to its causes. Thus, a single identical prescription is not advised to all patients. Sometimes, a food or drug that is laxative for a person would cause constipation in another person. Meanwhile, there are some general recommendations in IITM according which both prevention and treatment of constipation could be achieved in most people, including $(16,20,22,26)$ :

1. Chew food well.

2. Avoid of consuming foods that dry your bowel and lessen its mobility.

3. Avoid of consuming opiates and other constipationinducing drugs.

4. Set your meals in regular intervals.

5. Modify your body mal-temperament if it is hot.

6 . Modify your body mal-temperament if soda in your body is dominant.

7. Exercise regularly, particularly hiking and biking.

8. Drink more beverages, especially in hot environment or in case of severe physical activities.

9. Keep your body warm in cold conditions.

10. Do not hesitate to defecate in regular times.

11. Eat more fiber foods, particularly fresh fruits and vegetables, and wholemeal flour.

12. Be more active with regular exercises.

13. Change your oil feed to olive, canola, sesame, or high-quality purified animal oil.
Besides these general recommendations, treatment of constipation is also suggested according to IITM as following:

1. Diet therapy: Consumption of some food and fruits is advised to patients for treatment of constipation. For example, most vegetables like spinach, leek, lettuce, cabbage, fennel, and anise could remove constipation. Meanwhile, some vegetables such as tarragon and cress can deteriorate constipation. Moreover, dry fruits are more efficient to treat constipation than fresh fruits. Personal temperament must be considered in diet therapy. For example, cabbage, cucumber, and all types of plum are good choices in warm-temper persons; while in cold-temper persons, cooked fruits like cooked carrots, pears, figs, and some vegetables such as basil and leek are recommended.

2. Manipulative therapy: Some manual actions such as massaging the abdominal skin with warm oils, like castor, mastic, and lily oils can help to remove constipation. Moreover, if the lower abdominal skin is kept warm with proper clothing, the constipation will be relieved.

3. Medication: Some herbal and natural treatments have been advised in IITM resources to relieve constipation, which are classified in two large groups:

1. Laxative drugs: laxative (Molayyen) drugs are substances that can excrete waste materials just from gastrointestinal tract not from other parts of body. These drugs are usually weaker than purgative drugs with less side effects $(31,32)$. Some of the most important laxative drugs in IITM include cassia (folous), manna (tarangabin, Alhagi Persarum), brown sugar, shirkhesht (Cotoneaster Manna), and prune. Some of laxatives like cassia must be used with a corrector (Mosleh) to prevent from their adhesion to intestinal wall and subsequent ulcer. Others need no corrector, such as manna and shirkhesht. Using cassia flakes with sweet almond oil and boiling water or shirkhesht with sweet almond oil is advised at night before bedtime as a proper treatment for constipation $(16,22)$.

2. Purgative drugs: These include drugs by which waste materials can transfer from different organs to intestine then be excreted through gastrointestinal tract. Purgatives have more side effects than laxatives; therefore, their prescription is limited to severe constipation with no proper response to laxatives. Senna leaves are the most commonly used purgatives among people. It has some side effects such as cramps and diarrhea, which could be resolved by combined correctors. Red rose is a good corrector for senna leaves. One of the important problems toward using senna is drug resistance that could be prevented by concomitant use with laxative drugs. Aloe vera (Sabre zard) is another famous purgative with a strong effect that must not be prescribed without physician order due to its serious side effects $(22,32)$. 


\section{Discussion}

Chronic constipation in IITM is considered not only a gastrointestinal morbidity but also the mother of diseases like cancer, due to a chronic mal-temperament. Accordingly, when constipation lasts for a long time, the harmful humors would be accumulated in different organs leading to metabolic disorders and tumorigenesis events. Constipation in IITM is defined as defecation less than one time daily with firm and dry consistency. Some general recommendations of IITM help us to prevent and treat constipation; such as chewing food well, avoid of dry cold fiberless diet, regular aerobic exercise, and correction of body temperament. Moreover, diet therapy with high fiber fruits and vegetables, manipulative therapy such as abdominal massage with warm oils, and medication with herbal laxative or purgative drugs are specific therapeutic methods for constipation recommended by IITM scholars.

\section{References}

1. Vazquez Roque M, Bouras EP. Epidemiology and management of chronic constipation in elderly patients. Clin Interv Aging. 2015;10:91930. doi: 10.2147/CIA.S54304. [PubMed: 26082622].

2. Bharucha AE, Pemberton JH, Locke G3. American Gastroenterological Association technical review on constipation. Gastroenterology. 2013;144(1):218-38. doi: 10.1053/j.gastro.2012.10.028. [PubMed: 23261065].

3. Sonnenberg A, Koch TR. Physician visits in the United States for constipation: 1958 to 1986. Dig Dis Sci.1989;34(4):606-11. [PubMed: 2784759].

4. Choung RS, Branda ME, Chitkara D, Shah ND, Katusic SK, Locke G3, et al. Longitudinal direct medical costs associated with constipation in women. Aliment Pharmacol Ther. 2011;33(2):251-60. doi: 10.1111/j.13652036.2010.04513.x. [PubMed: 21091523].

5. Choung RS, Shah ND, Chitkara D, Branda ME, Van Tilburg MA, Whitehead WE, et al. Direct medical costs of constipation from childhood to early adulthood: a population-based birth cohort study.J Pediatr Gastroenterol Nutr. 2011;52(1):47-54. doi: 10.1097/MPG.0b013e3181e67058. [PubMed: 20890220].

6. Woodward S. Assessment and management of constipation in older people. Nurs Older People. 2012;24(5):21-6. doi: 10.7748/nop2012.06.24.5.21.c9115. [PubMed: 22792697]

7. Belsey J, Greenfield S, Candy D, Geraint M. Systematic review: impact of constipation on quality of life in adults and children. Aliment Pharmacol Ther. 2010. doi: 10.1111/j.1365-2036.2010.04273.x.

8. Irvine EJ, Ferrazzi S, Pare P, Thompson WG, Rance L. Health-related quality of life in functional GI disorders: focus on constipation and resource utilization. Am J Gastroenterol. 2002;97(8):1986-93. doi: 10.1111/j.1572-0241.2002.05843.x. [PubMed: 12190165].
9. Sun SX, Dibonaventura M, Purayidathil FW, Wagner JS, Dabbous O, Mody R. Impact of chronic constipation on health-related quality of life, work productivity, and healthcare resource use: an analysis of the National Health and Wellness Survey. Dig Dis Sci. 2011;56(9):2688-95. doi: 10.1007/s10620-011-1639-5. [PubMed: 21380761].

10. El-Salhy M, Svensen R, Hatlebakk JG, Gilja OH, Hausken T. Chronic constipation and treatment options (Review). Mol Med Rep. 2014;9(1):3-8. doi: 10.3892/mmr.2013.1770. [PubMed: 24189940].

11. Shemerovskii KA. [Constipation-a risk factor for colorectal cancer] Klin Med (Mosk). 2005;83(12):60-4. [PubMed:16502728].

12. Watanabe $T$, Nakaya N, Kurashima K, Kuriyama S, Tsubono $Y$, Tsuji I. Constipation, laxative use and risk of colorectal cancer: The Miyagi Cohort Study. Eur J Cancer. 2004;40(14):2109-15. doi 10.1016/j.ejca.2004.06.014. [PubMed: 15341986].

13. Roberts MC, Millikan RC, Galanko JA, Martin C, Sandler RS. Constipation, laxative use, and colon cancer in a North Carolina population. Am J Gastroenterol. 2003;98(4):857-64. doi: 10.1111/j.15720241.2003.07386.x. [PubMed: 12738468].

14. Brown E. Islamic Medicine. 5th ed. Tehran: Scientific and cultural publication; 1992.

15. Najmabadi M. History of medicine in Iran after Islam. Tehran: Tehran University; 1987.

16. Hamedi S, Jokar A, Abbasian A. Viewpoints of Iranian traditional medicine (ITM) about etiology of constipation.J Gastroint Dig Syst S. 2012;8(2):12.

17. Naseri M. A review on Iranian traditional medicine principles. 10 ed. Iranian traditional medicine publication; 2013.

18. Drossman DA. The functional gastrointestinal disorders and the Rome III process. Gastroenterology. 2006;130(5):1377-90. doi: 10.1053/j.gastro.2006.03.008. [PubMed: 16678553].

19. Aghili MH. Kholasat-ol-Hekmaa. Tehran: Ismaeelian Publisher; 2011.

20. Avicenna . Canon of Medicine. 3th ed. Tehran: Soroosh Publisher; 1989

21. Khorasani A, Shirazi MH. Gharabadian-e-Kabir. 2 ed. Tehran: Mahmoudi publication; 2000.

22. Elsagh M. Constipation in traditional Iranian medicine. 2012;2(4):36170 .

23. Gorgani I. Al-Igraz Al-Tibbieh and Al-Mabahis al-Alaieh. 1th ed. Tehran: University Press; 2005.

24. Meysari . Alaii daneshname. 1th ed. Tehran: Tehran University Press; 1994.

25. Nafis IE. Sharh al-Asbab va al-Alamat. 1th ed. Tehran: Jalal Publisher; 2008.

26. Gorgani S. Zakhire-ye-Kharazmshahi. 3 ed. Iranian Medical Science Culture publication; 2003.

27. Azam Khan M.Aksir Azam.1th ed. Tehran: Institute of Medicine Studies and Islamic Medicine Press; 2004.

28. Arzani MA. Akbari medicine. 1th ed. Tehran: Jalal Publisher; 2008.

29. Folden SL. Practice guidelines for the management of constipation in adults. Rehabil Nurs. 2002;27(5):169-75. [PubMed: 12242866].

30. Schiller LR. Review article: the therapy of constipation. Aliment Phar macol Ther. 2001;15(6):749-63. [PubMed: 11380313]

31. Khorasani A. Makhzan-ol-advieh. Tehran: Tehran University Press;

32. Mozaffarpour S. Introduction of single drugs efficient to trat constipation in Iranian traditional medicine. History Med. 2011;3(9):79-95. 